\title{
LA DURACIÓN COMO AXIOLOGÍA DE LA ETOLOGÍA POLÍTICA DE SPINOZA
}

\author{
Stéphane Vinolo \\ Pontificia Universidad Católica del Ecuador \\ Escuela de Filosofía, Quito - Ecuador \\ svinolo@puce.edu.ec
}

\begin{abstract}
RESUMEN / ABSTRACT
El problema de la evaluación en política presenta la dificultad del querer comparar, jerarquizar y por lo tanto cuantificar valores que se presentan bajo la modalidad de la cualidad. Para poder salir de esta dificultad, Spinoza propone una política plenamente inmanente en la cual el único criterio de evaluación es el de la duración. Así entendemos por qué Spinoza pudo afirmar, en pleno siglo XVII, el carácter absoluto en todo de la democracia, no en razón de los valores que promueve sino, al contrario, en razón de su capacidad a durar de manera inmanente.

PalABRAS ClaVE: axiología, democracia, duración, etología, evaluación, Spinoza, valores.

\section{DURATION AS AN AXIOLOGY OF THE POLITICAL ETHOLOGY IN SPINOZA}

The problem of evaluation in politics is no less than the one of quantifying qualities. In order to evaluate the opportunity of political regimes or governments, one must be able to find a common factor thanks to which one will be able to compare them from an objective point of view. In the immanent political philosophy of Spinoza, this common factor is duration. Therefore, we can understand how Spinoza has been able to affirm democracy as the absolute regime, non-because it promotes absolute and definitive values, but on the contrary, because democracy, due to its inherent rationality, last much more than any other regime.
\end{abstract}

KEYWORDS: Axiology, democracy, duration, ethology, evaluation, Spinoza, values. 
“[...], el poder del Estado y, por lo mismo, su derecho, deben ser medidos por el número de ciudadanos" (Spinoza 1986, 191)

"[...], ici comme partout, le nombre change tout.

Quantity is of the essence" (Camus 2011,14)

\section{Introducción}

$\overline{R A}$ Tal como lo escribía Bergson en las últimas líneas de su tesis doctoral, es probable que la matriz de los más grandes problemas filosóficos sea una confusión entre la cualidad y la cantidad ${ }^{1}$. Estos conceptos resuenan en múltiples debates de las ciencias humanas y sociales en las cuales se oponen defensores de métodos cuantitativos y cualitativos. Pero más allá de una oposición entre métodos, estos conceptos tienen un impacto a niveles conceptuales más profundos. El simple hecho de que podamos hablar, en ética, de "escala de valores", es el rastro que solemos sobreponer evaluaciones cuantitativas, cuyo paradigma es el de la clasificación sobre una escala, con evaluaciones cualitativas que encontramos en todos los discursos que se expresan en términos de valores. Dado que los valores son cualitativamente diferentes -tal como podemos ver por ejemplo con la libertad, igualdad y fraternidad, es difícil entender cómo colocarlos sobre una escala con la cual evaluarlos, puesto que no disponen de ningún punto de contacto que pueda servir de patrón a dicha evaluación. Si queremos compararlos para evaluarlos, ¿cuál sería la unidad de medida de la escala? ¿Cómo determinar por ejemplo si la libertad es superior a la igualdad, y que debería ser por lo tanto el valor fundamental de un país, ya que las diferencias entre estos dos valores son cualitativas, por lo que no parecen inferiores ni superiores, pero simplemente diferentes?

Este problema se refleja de manera paradigmática en filosofía política, a la hora de distinguir, entre los regímenes políticos posibles, el mejor o el más deseable de todos. Toda evaluación supone un patrón común a partir del cual evaluar, y este patrón suele ser cualitativo para poder determinar jerarquías. Ciertos filósofos afirmarán por ejemplo que la democracia es el mejor régimen porque es más igualitario, otros que es más bien la aristocracia porque es más eficiente, otros en fin que es la dictadura militar ya que produce más orden y seguridad. Cada vez, es un valor cualitativo que les permite ordenar los regímenes políticos sobre una escala según se acerquen más o menos a este valor. Sin embargo, al escoger un valor cualitativo como patrón de evaluación, nos exponemos al problema de la legitimidad y de la difícil justificación de escoger tal

1 "El problema de la libertad ha nacido, pues, de un malentendido: ha sido para los modernos lo que fueron para los antiguos los sofismas de la escuela de Elea y, como esos mismos sofismas, tiene su origen en la ilusión por la que se confunde sucesión y simultaneidad, duración y extensión, cualidad y cantidad” (Bergson 1999, 16). 
patrón cualitativo. ¿Cómo determinar si el valor más alto de la política es la igualdad, la eficiencia o la seguridad? Raymond Aron, en su última clase dictada en el Collège de France el 4 de abril de 1978, notaba este punto a la hora de cuestionar el porvenir de las democracias liberales a raíz de la manera según la cual iban a articular sus dos valores fundamentales: libertad e igualdad (Aron 2013). ¿Cómo decidir si la democracia debe priorizar la libertad o la igualdad dado que no podemos comparar de manera objetiva estos dos valores según un criterio común a ambos? Más aun, no solo no podemos comparar objetivamente dos valores cualitativos, sino además existen en el seno de cada uno de los valores cualitativos, diferencias cualitativas de segundo nivel que reproducen la misma dificultad. Una vez que una sociedad haya aceptado que su valor fundamental es, por ejemplo, el de la igualdad, ¿cómo determinar de manera objetiva si debemos aplicar la igualdad liberal de derechos, la igualdad socialista de condiciones o la igualdad de oportunidades? Así, dado que los valores son cualitativamente diferentes, es imposible ubicarlos sobre una misma escala cuantitativa para compararlos de manera objetiva con el fin de determinar relaciones de superioridad entre ellos. Podríamos así imaginar que el diálogo en filosofía política, al nivel más profundo que es el de la jerarquización de los regímenes políticos es imposible ya que se basa en preferencias cualitativas subjetivas y por lo tanto incomparables.

Para salir de esta contradicción, es necesario encontrar un patrón objetivo, un patrón que todos podamos medir, comparar y analizar, para clasificar las políticas y los regímenes políticos. ¿Debemos entonces preguntarnos si es posible determinar un valor estrictamente cuantitativo, o más bien hacer de una cuantificación objetiva, un patrón o un valor? La respuesta a esta pregunta es positiva y yace en la filosofía de Spinoza, paradigma del momento moderno y por lo tanto del momento cuantitativo de la filosofía (Ramond 1995). Si bien Descartes había comenzado a rechazar las cualidades ocultas escolásticas para someter la totalidad de la fenomenalidad, tanto interna como externa, al orden y a la medida ${ }^{2}$, es decir a lo que se puede medir, Spinoza intentó culminar este proyecto de la cuantificación radical y generalizada ${ }^{3}$. En esta radicalización cuantitativa podemos

2 “[...] al cabo se nota que solamente aquellas [disciplinas] / en las que se estudia cierto orden y medida hacen referencia a la Mathesis, y que no importa si tal medida ha de buscarse en los números, en las figuras, en los astros, en los sonidos o en cualquier otro objeto; y que, por lo tanto, debe haber una cierta ciencia general que explique todo lo que puede buscarse acerca del orden y la medida no adscrito a una materia especial, y que es llamada, no con un nombre adoptado, sino ya antiguo y recibido por el uso, Mathesis Universalis, ya que en ésta se contiene todo aquello por lo que las otras ciencias son llamadas partes de la Matemática" (Descartes 1984, 86). Para una interpretación global de este punto podremos ver (Marion 2008). Tal como lo mostró de manera precisa y abundante Jean-Luc Marion, el hecho de que Descartes haya intentado rechazar la cualidad a favor de la cantidad, no significa que haya logrado hacerlo puesto que tanto el infinito (Marion 1986) como la Carne (Marion 2013) no se intengran a este proceso.

"Verdaderamente, no puedo dejar de asombrarme de que un filósofo [Descartes] que había decidido firmemente no deducir nada sino de principios evidentes por sí, ni afirmar nada que no percibiese clara y distintamente, y que había censurado tantas veces a los escolásticos 
encontrar una solución al problema de la evaluación en política. El valor inmanente y cuantitativo que propone Spinoza para evaluar no solo la política sino además cualquier campo del ser, es la duración. No todos podemos saber si tal régimen político es más igualitario o más eficiente económicamente que otro, y menos aún podemos saber si un régimen político se debe evaluar según la igualdad o la eficiencia económica; sin embargo, todos podemos constatar de manera objetiva cuál es el régimen político que más dura. Por lo tanto, el consenso es más fácil de encontrar en un patrón que todos podamos medir. Muy lejos de buscar valores cualitativos trascendentes incomparables entre ellos, Spinoza propone una etología política basada en el único criterio de la duración inmanente de todas las cosas singulares. Pero paradójicamente, al rechazar los valores, tal como vamos a verlo, Spinoza puede, de manera única en pleno siglo XVII, afirmar el carácter no solo absoluto, sino además absoluto en todo, y por lo tanto insuperable, de la democracia ${ }^{4}$. Así, muy lejos de los autores contemporáneos que defienden a la democracia por razones axiológicas vinculadas a la defensa de ciertos valores, Spinoza nos permite pensar que la fuerza de la democracia es al contrario el no darse ningún valor a priori sino el producir valores de manera a posteriori (Ramond 2016).

\section{La obsesión de la cuantificación}

Hay, en la filosofía de Spinoza, una verdadera voluntad de lucha en contra de todos los autores que han pensado en términos de cualidades, de virtudes o de potencialidades. En su Carta 56 a Hugo Boxel, podemos ver que apenas Spinoza ataca concepciones filosóficas opuestas a la suya, es el concepto de cualidad que aparece, y surge junto a conceptos valorados de manera negativa, por no decir valorados de manera ridícula ${ }^{5}$. Si extendemos estas reflexiones sobre las cualidades ocultas al campo de las ciencias sociales, es adecuado afirmar que, para un mecanicista como lo es Spinoza, los problemas ontológicos que presentan las cualidades ocultas se evidencian a la hora de querer utilizar conceptos tales como los de carisma o de poder, conceptos que, al representar cualidades ocultas, son tan incomprensibles y misteriosos como lo es para la ciencia

el que hubieran querido explicar cosas oscuras mediante cualidades ocultas, parta de una hipótesis más oculta que cualquier cualidad oculta” (Spinoza 1987 V Prefacio, 418).

4 "Transeo tandem ad tertium et omnio absolutum imperium, quod democraticum appellamus", (Spinoza 2005 XI 1, 268).

5 "No pesa mucho sobre mí la autoridad de Platón, Aristóteles y Sócrates. Me habría sorprendido, si usted hubiese citado a Epicuro, a Demócrito, a Lucrecio o a alguno de los atomistas o defensores de los átomos; pues no ha de sorprendernos que aquellos que inventaron las Cualidades Ocultas, las Especies intencionales, las Formas sustanciales y otras mil necedades, hayan fraguado los Espectros y Fantasmas y hayan creído a las viejezuelas para menoscabar la autoridad de Demócrito, de cuya buena fama estaban tan envidiosos que quemaron todos los libros que él había publicado con tanto encomio" (Spinoza 2007, 222-223). 
contemporánea la antigua virtud dormitiva del opio tan alabada por los médicos de Molière.

El rechazo de la cualidad se cristaliza de manera paradigmática en la ontología fundamental de Spinoza, llevando la lucha mucho más allá de la aplicación de un simple método científico cuantitativo. Se manifiesta de manera paradigmática en una nueva concepción de la esencia. Solemos entender por esencia en el lenguaje común, lo que permanece detrás del cambio. Del bebé al anciano, la persona conserva cierta esencia que la determina como "la misma persona" a lo largo de su vida. Para quienes piensan que existe una esencia de la democracia, esta esencia no se confunde con tal o tal democracia existente, sino que se encuentra detrás de todas estas, ya que participan de ella sin encarnarla completamente. Contra esta disimetría común entre la esencia y la cosa, Spinoza propone reducir la distancia y sobreponer esencia y cosa: "Digo que pertenece a la esencia de una cosa aquello dado lo cual la cosa resulta necesariamente dada, y quitado lo cual la cosa necesariamente no se da; o sea, aquello sin lo cual la cosa -y viceversa, aquello que sin la cosa- no puede ni ser ni concebirse" (Spinoza 1987 II def. 2, 122). Ahora, esta superposición nos lleva de manera inevitable hacia el matematismo de Spinoza, dado que esta nueva definición, que no distingue la esencia de la cosa de la cual es la esencia, es particularmente adecuada al caso de los objetos matemáticos. Efectivamente, si damos la definición del círculo, tenemos el círculo, y si damos el círculo, tenemos su definición o su esencia. Este matematismo como paradigma de la esencia se ve reforzado por los mismos ejemplos utilizados por Spinoza a la hora de presentar su teoría de la esencia. En Ética, II, 49, Spinoza escribe que: "En el alma no se da ninguna volición, en el sentido de afirmación y negación, aparte de aquella que está implícita en la idea en cuanto que es idea" (Spinoza 1987 II 49, 193). La afirmación que surge en el alma no proviene entonces de una facultad misteriosa llamada voluntad, sino de la misma idea que se auto-afirma. Sin embargo, a la hora de demostrar esta proposición, Spinoza toma un ejemplo muy preciso y específico de esencia, que resulta ser el ejemplo de un objeto matemático: "Siendo así, concibamos una volición singular, por ejemplo, un modo del pensar por el que el alma afirme que los tres ángulos de un triángulo valen dos rectos" (Spinoza 1987 II 49 dem., 194). Es porque este ejemplo proviene de las matemáticas que podemos entender que la idea afirme este objeto, o más bien dicho, tal como lo escribe Spinoza, que esta afirmación es su esencia: "De esta suerte (por la Definición 2 de esta Parte), esa afirmación pertenece a la esencia de la idea del triángulo, y no es otra cosa que ella misma" (Spinoza 1987 II 49 dem., 194). Al contrario, como ningún objeto físico depende directamente de la definición que podamos dar de éste, las esencias de los objetos del mundo físico complicarían la aplicación de la nueva concepción de la esencia de Spinoza. Por esta razón, notemos que cuando Spinoza abandona momentáneamente los ejemplos matemáticos explícitos para pasar a ejemplos del mundo de la física, utiliza el de un caballo. Pero, una vez más, este caballo no es cualquiera. El caballo del cual trata Spinoza es un caballo que no existe en el mundo físico. Se trata de un caballo con alas: "Pues ¿qué es «percibir» un caballo alado, sino afirmar del caballo que tiene alas?" (Spinoza 1987 II 49 Esc., 194). Así, incluso cuando Spinoza se aleja de los ejemplos matemáticos, se refugia inmediatamente en objetos imaginarios puesto que, para estos también, como dependen 
exclusivamente de la definición que decidamos darles, sus esencias se confunden con lo que son, tal como si Spinoza tratara toda esencia como una esencia matemática.

El matematismo de la esencia se extiende lógicamente al problema de la individuación, donde se evidencia el carácter fundamental de la cuantificación al nivel ontológico. Sin duda, el espinosismo es una filosofía de las cosas singulares $<$ res singulares $>$; sin embargo, la delimitación de éstas es problemática. Lo es en cada filosofía, puesto que toda filosofía debe determinar sus flujos y sus cortes (Deleuze 1972). Podemos así preguntar en dónde debe pasar la frontera de "la noche" o de "la niñez" dentro de los flujos que nos llevan del crepúsculo al alba y del nacimiento a la muerte. Los cortes cualitativos de flujos cuantitativos son problemáticos para toda filosofía, desde que Platón, en el Fedro, hizo del filósofo un carnicero cuyo papel es el recortar la realidad respetando sus articulaciones naturales: “[...], hay que poder dividir las ideas siguiendo sus naturales articulaciones, y no ponerse a quebrantar ninguno de sus miembros, a manera de un mal carnicero" (Platón 1986 265e, 385). En Spinoza, dado que la esencia no se esconde detrás de los múltiples cambios que padecen las cosas, la individuación también se hace de manera cuantitativa, mediante el mantenimiento de "cierta relación" individualizante, y no por cierta cualidad íntima de la cosa:

Cuando ciertos cuerpos, de igual o distinta magnitud, son compelidos por los demás cuerpos de tal modo que se aplican unos contra otros, o bien -si es que se mueven con igual o distinto grado de velocidad- de modo tal que se comuniquen unos a otros sus movimientos según una cierta relación, diremos que esos cuerpos están unidos entre sí y que todos juntos componen un solo cuerpo, o sea, un individuo que se distingue de los demás por medio de dicha unión de cuerpos (Spinoza 1987 II 13 def., 146).

Desgraciadamente, la traducción española "una cierta relación" de Vidal Peña, excelente en muchas ocasiones, no refleja en este caso perfectamente al latín <certâ quâdam ratione $>$. El texto latín es más preciso, y no habla de cierta relación -indefinida, sino al contrario de una relación precisa. La palabra $<$ certâ $>$ se refiere en este caso a una relación "precisa y determinada". Así, lo que individua un cuerpo es una relación precisa y determinada entre los movimientos de sus partes, lo que tiene consecuencias directas en el campo de la política, dado que una sociedad o un Estado también son cosas singulares. Mientras persevere esta relación determinada entre sus partes, el individuo como tal existe y persevera en su ser, pero si esta relación se sale de ciertos límites, deberemos asumir que estamos frente a otro individuo. Podemos justificar esta lectura de una cuantificación de los individuos con la ayuda de dos textos. En el primero, Spinoza propone una cuantificación precisa de esta relación individual determinada. Tal como podemos ver en el Tratado breve, Spinoza muestra que lo que constituye un individuo es una proporción, valorada en este ejemplo como proporción de 1 a 3 , es decir, muy precisamente determinada ${ }^{6}$. La segunda confirmación de esta

6 "Pero, si otros cuerpos actúan sobre el nuestro tan violentamente, que no puede mantenerse la proporción de 1 a 3 del movimiento, eso constituye la muerte, y una aniquilación del 
cuantificación de la individuación se encuentra en el pensamiento de la muerte, es decir, en la descomposición de la relación precisa que el individuo es. En el Escolio de la proposición 39 de la cuarta parte de la Ética, Spinoza evoca el caso de un poeta español que, después de haber padecido cierta enfermedad, plantea la pregunta de la ipseidad $^{7}$. Dado que la relación cuantitativa constitutiva de su ser se ha modificado radicalmente, su ser ha cambiado cualitativamente por lo que ya no es la misma persona. La posición de Spinoza es radical, al concebir la individuación de manera exclusivamente cuantitativa, casi cualquier transformación de una persona amenaza con ser una transmutación entre personas. Así, la cuantificación es en Spinoza una obsesión que impacta mucho más allá de la simple aplicación de un método científico y que, al determinar toda la ontología, impacta en la política, puesto que la segunda no es nada más que el despliegue de la primera.

\section{Cuantificación y política: hacia una etología humana}

La filosofía política de Spinoza es la continuación lógica de este movimiento, lo que implica no solo una política muy específica, sino además una concepción muy particular de lo que se llama política. La tesis más original de Spinoza es probablemente, tal como podemos ver en el Tratado Político, la identidad o una superposición de la potencia y del derecho: "De ahí que el derecho natural de toda la naturaleza y, por lo mismo, de cada individuo se extiende hasta donde llega su potencia" (Spinoza 1986 II 4, 2013) ${ }^{8}$. Esta definición del derecho marca el vínculo entre política y ontología en un gesto de continuación de la potencia de la naturaleza dentro del Estado civil. La continuidad entre política y ontología se extiende en una misma concepción naturalista del concepto de ley. Hay en Spinoza un fisicalismo de la política en este sentido que el modelo de la ley, incluso en política, son las leyes de la naturaleza y de la física. De allí que algunos comentaristas hayan visto en su voluntad de preservar un modelo político estrictamente cuantitativo, la explicación del abandono del modelo del contrato social entre el Tratado Teológico-político y el Tratado Político (Ramond 2016). Efectivamente, la estructura del contrato social supone una ruptura cualitativa entre el estado precontractual y la sociedad civil, ruptura que Spinoza comenzó por aceptar en el capítulo XVI del Tratado

alma, en cuanto que ella es tan solo una idea, conocimiento, etc., de este cuerpo con esta proporción de movimiento y reposo" (Spinoza 1990 II prefacio nota 14, 100).

7 "[...]; así, he oído contar acerca de cierto poeta español que, atacado de una enfermedad, aunque curó de ella, quedó tan olvidado de su vida pasada que no creía fuesen suyas las piezas teatrales que había escrito, y se le habría podido tomar por un niño adulto si se hubiera olvidado también de su lengua vernácula” (Spinoza 1987 IV 39 Esc., 360).

$8 \quad$ Modifico la traducción de Atilano Domínguez ya que el texto latín no dice potestas sino potentia, lo que implica traducir por potencia y no por poder. 
Teológico-Político ${ }^{9}$, pero que eliminó del Tratado Político al explicar el surgimiento del Estado únicamente mediante las combinaciones de potencias. Así, el Tratado Político restablece una continuidad cuantitativa entre los dos momentos de la vida prepolítica y política haciendo del estado civil el momento de la combinación de las potencias, de la misma manera que podían combinarse o no en el estado de naturaleza. En este último texto, no hay ruptura cualitativa. La única diferencia del estado civil es que favorece los encuentros beneficiosos, o como dice Deleuze, organiza los encuentros (Deleuze 1996, 253) que permiten combinaciones positivas de potencias, cuando el estado de naturaleza deja esos encuentros darse al azar, sin maximizar las chances que sean beneficiosos. En fin, para confortar la idea del fisicalismo antropológico y político de Spinoza -fisicalismo que proviene de la cuantificación de las esencias singulares, se puede recordar que en el primer capítulo del Tratado Político, Spinoza afirma que va a considerar las acciones humanas, así como las pasiones, como si fueran fenómenos naturales ${ }^{10}$.

Dado que la cuantificación de la potencia determina todas las cosas singulares en Spinoza, su política se despliega en una etología humana. Si las esencias están determinadas por su potencia y de manera positiva como actividad de afirmación de sí mismo, se explica que Spinoza esté interesado en la exterioridad de los seres y no en su interioridad. De la misma manera que la lucha de Spinoza es una lucha de la cuantidad contra la cualidad, es también lógicamente, en el campo de la política, una lucha de la exterioridad en contra de la interioridad. Esta lucha se evidencia de manera prioritaria en lo que se exige de los gobernantes. En contra de los sistemas filosóficos que apuestan por príncipes virtuosos, o de los sistemas filosóficos que dedicaron tanta energía al análisis de la educación de los gobernantes, Spinoza pretende construir un sistema político puramente consecuencialista, sin preocuparse de la pureza de las intenciones de los gobernantes. Lo importante no es por qué motivo interior los gobernantes actúan bien, lo importante es que lo hagan: "Pues para la seguridad del Estado no importa qué impulsa a los hombres a administrar bien las cosas, con tal que sean bien administradas" (Spinoza 1986a I 6, 104). Simétricamente, la valoración de la etología externa se encuentra en la teoría de la dominación, a la hora de explicar por qué razón los individuos deben obedecer al Estado. O más bien dicho, a la hora de no explicar por qué los sujetos deben obedecer a las leyes promulgadas por el Estado: "Porque lo que hace al súbdito, no es el motivo de la obediencia, sino la obediencia misma" (Spinoza 1986b XVII 1, 354). Tanto del lado de los gobernantes como del lado

9 "Por eso debieron establecer, con la máxima firmeza y mediante un pacto, [...]” (Spinoza 1986b XVI 2, 338).

10 " $[. .$.$] , me he esmerado en no ridiculizar ni lamentar ni detestar las acciones humanas, sino$ en entenderlas. Y por eso he contemplado los afectos humanos, como son el amor, el odio, la ira, la envidia, la gloria, la misericordia y las demás afecciones del alma, no como vicios de la naturaleza humana, sino como propiedades que le pertenecen como el calor, el frío, la tempestad, el trueno y otras cosas por el estilo a la naturaleza del aire" (Spinoza 1986a I 4, 101-102). 
de los gobernados, lo importante es la acción que tiene consecuencias adecuadas, que evita la sedición de la sociedad, y no sus razones profundas. En todos los casos, las valoraciones en política se hacen a partir de comportamientos exteriores observables, y no a raíz de las intenciones o de motivos internos.

La exterioridad se reafirma en fin de manera precisa en el análisis del tipo de acción que espera el gobernante de los gobernados, ya que este se limita a la simple obediencia. Una vez más, no importa por qué razón los individuos obedecen, lo importante es que lo hagan. Podríamos aquí oponer la obediencia y el consentimiento mediante los conceptos de "aceptación de una ley externa" y de "aceptación de una ley interna", en este sentido que consentir, es someterse a una ley interna cuando obedecer, es someterse a una ley externa. Ahora, constatamos en Spinoza una valoración extrema de la obediencia por encima del consentimiento. A tal punto que, si un hombre plenamente racional está confrontado al problema de tener que obedecer a una ley irracional, debe sacrificar sus ideas para someterse a la ley irracional, siempre y cuando esta sea la ley de la mayoría. Pero paradójicamente, este gesto no es un abandono de la racionalidad sino una aplicación de ésta, puesto que, al obedecer a la ley de la mayoría, aunque esta sea irracional, el sujeto evita entrar en conflicto con la sociedad y poner en peligro su cohesión. Así, si para evitar la desagregación total de la sociedad, que nos llevaría a la violencia de todos contra todos, es preferible -y por lo tanto racional- someterse a leyes no plenamente racionales, tal como si la racionalidad fundamental del perseverar en el ser fuese superior a la racionalidad de leyes particulares. La obediencia externa y comportamental es así la opción racional en un cálculo de costos y beneficios, aunque esta racionalidad implique obedecer a leyes irracionales: "Por consiguiente, si un hombre que se guía por la razón tuviera un día que hacer, por orden de la sociedad, algo que, a su juicio, contradice la razón, ese perjuicio queda ampliamente compensado por el bien que surge del mismo estado político. Pues también es una ley de la razón que, de dos males, se elija el menor" (Spinoza 1986a III 6, 131). Aunque pueda parecernos sorprendente en filosofía contemporánea, vemos claramente en los textos que, para Spinoza, es mejor obedecer a leyes irracionales, que vivir en una situación en la cual cada uno pueda rechazar las leyes en nombre de sus propios valores interiores, ya que esto nos llevaría al estado de la guerra de todos contra todos. Notemos en esta dirección que la exigencia de obediencia es tan fuerte que el ciudadano ni siquiera puede interpretar las leyes: "Por otra parte, tampoco podemos concebir que esté permitido a cada ciudadano interpretar los decretos o derechos de la sociedad. Pues, si le estuviera permitido, cada uno sería ipso facto su propio juez, ya que no le sería nada difícil excusar o revestir de apariencia jurídica sus actos" (Spinoza 1986a III 4, 129). Así, la obediencia debe ser completa, y puesta una ley, cada ciudadano debe someterse a ella en su comportamiento, aunque de manera interna, pueda no estar de acuerdo con esta. Aunque estos textos de Spinoza puedan parecernos difícilmente aceptables, puesto que las experiencias políticas del siglo XX nos han mostrado de manera abundante los límites de la obediencia a leyes mayoritarias, debemos explicar la lógica del sistema espinozista para dar sentido a sus textos y entender en qué medida parece excluir de su sistema el mismo concepto de legitimidad (Lordon 2013) para limitarse a pensar la legalidad: 
[...], cada ciudadano no es autónomo, sino que depende jurídicamente de la sociedad, cuyos preceptos tiene que cumplir en su totalidad, y no tiene derecho a decidir qué es justo o inicuo, piadoso o impío. Antes, al contrario, como el cuerpo del Estado se debe regir como por una sola mente y, en consciencia, la voluntad de la sociedad debe ser considerada como la voluntad de todos, hay que pensar que cuanto la sociedad considera justo y bueno ha sido decretado por cada uno en particular. Por eso, aunque un súbdito estime que las decisiones de la sociedad son inicuas, está obligado a cumplirlas (Spinoza 1986a III 5, 129).

Esta concepción de la política es sorprendente, ya que solemos pensar que existe una legitimidad basada en ciertos valores por encima de la legalidad; legitimidad en nombre de la cual se puede desobedecer, en algunos casos precisos, a ciertas leyes del Estado. De hecho, las teorías contemporáneas de la desobediencia civil (Pedretti 2001) se basan en gran medida en esta diferencia entre legalidad y legitimidad. Es también sorprendente porque muchos autores piensan que la obediencia total es la marca del autoritarismo cuando Spinoza hace de ésta una necesidad en una democracia pensada como absoluta en todo. Spinoza excluye así de su sistema la legitimidad y la posibilidad de desobedecer en nombre de valores, afirmando que los únicos valores a los cuales alguien puede referirse son paradójicamente los de la ley positiva. Nadie puede invocar valores suyos en contra de éstos, lo que parece muy difícil de aceptar, pero a la vez plenamente explicable en una teoría que se focaliza sobre una etología política: “[...] los derechos civiles tan solo dependen del decreto de la sociedad, y ésta no tiene que complacer a nadie, sino solo a sí misma, para mantenerse libre, ni tiene que admitir bien o mal, aparte del que ella estima tal" (Spinoza 1986a IV 5, 145-146). Si tal como lo hemos visto al nivel ontológico, lo fundamental es la ley según la cual cada cosa singular hace esfuerzo para perseverar en su ser ${ }^{11}$, el perseverar en su ser está más racionalmente realizado en un Estado que en una guerra civil de todos contra todos, cuales sean las patologías de éste. El gobernante tiene entonces un poder casi ilimitado; sin embargo, un solo límite muy importante abre la posibilidad de una regulación social que se hace según las potencias y no según los valores. Ningún Estado que tenga una política radicalmente contraria a los intereses de los sujetos puede perseverar en su ser mucho tiempo, por el simple hecho que la indignación que producirá será tal que los ciudadanos unirán sus potencias para tumbarlo (Matheron 2011). Al entrar en contradicción con los intereses de los individuos, generará contra él potencias sociales que, al unirse en la fuerza de la multitud, lo van a amenazar y algún día eliminar: "Hay que considerar, en tercer y último lugar, que cuanto provoca la indignación en la mayoría de los ciudadanos es menos propio del derecho de la sociedad" (Spinoza 1986a III 9, 134). Pero notemos que lo que hace que una medida política sea mala, no es en este caso su inadecuación

11 Esta ley fundamental está expresada con los términos cualitativos del quantum: “Cada cosa se esfuerza, cuanto está a su alcance, por perseverar en su ser" (Spinoza 1987 III 6, 220). Desgraciadamente, la traducción de Vidal Peña no refleja el vínculo directo entre ser y cuantificación que indica claramente la expresión latín <in quantum est $>$ que debería ser traducida por "en cuanto es" y no "en cuanto está a su alcance". 
con valores que preexisten a la ley, sino la simple potencia cuantitativa de las personas indignadas que produce, lo que ya nos permite acercarnos al problema de la duración como valor inmanente.

Por el papel que da tanto a la obediencia como a la indignación, podríamos pensar que esta política espinozista es brutal y autoritaria. Sin embargo, se puede mostrar exactamente lo contrario (Vinolo 2015). Por un lado, dado que ningún valor a priori rige a la democracia espinozista porque sus valores solo surgen del voto, toda reivindicación social o política es legítima, sin que se pueda decir que tal reivindicación es ilegítima porque se opone a los valores fundamentales de la democracia. A la vez, dado que la única fuerza de las leyes es la levedad matemática de la mayoría, ninguna mayoría puede imponer el bien ni la verdad. Las leyes no son nada más que el reflejo de la voluntad del pueblo o del balance de las potencias de los grupos sociales en un momento dado, y por lo tanto pueden ser modificadas cuando la mayoría cambie. La sustitución de la potencia de la multitud al absoluto de los valores permite paradójicamente establecer una sociedad más leve, en la cual todas las ideas puedan ser defendidas de manera legítima, aunque solo puedan ser aplicadas después de haber pasado por el proceso legislativo y mayoritario.

\section{La duración como suplemento de los valores}

Visto el rechazo de las cualidades tanto en ontología como en política, podemos responder a la pregunta del patrón de la evaluación de los regímenes políticos. Esta no es una cuestión artificial que introducimos en Spinoza. Se encuentra en sus mismos textos: "Cuál es la mejor constitución de un Estado cualquiera se deduce fácilmente del fin del estado político, [...]" (Spinoza 1986a V 2, 149). Para evaluar los diferentes regímenes políticos, uno piensa tradicionalmente que necesitamos saber cuál es la finalidad de la política, para poder determinar cuál de ellos mejor cumple con ésta. Por un lado, la finalidad de la política está claramente determinada en el Tratado Teológico-Político: "El verdadero fin del Estado es, pues, la libertad" (Spinoza 1986b XX 2, 415). Pero, el Tratado Político presenta una versión más dura de ésta, dado que la finalidad de la política ya no es nada más que: "[...] la paz y la seguridad de la vida" (Spinoza 1986b V 2, 149). Para los contemporáneos, esta finalidad minimalista es casi inaceptable, pero tiene una justificación a la vez histórica y conceptual. Efectivamente, puede ser atribuida primero a un hecho histórico. Spinoza fue testigo del linchamiento de los hermanos De Witt el 20 de agosto 1672, lo que lo llevó a insistir cada vez más sobre la necesidad de la obediencia, y a desconfiar de los movimientos de la muchedumbre que no se debe confundir con la mayoría democrática (Vinolo 2013). Pero debemos buscar la explicación de este cambio en un nivel conceptual más profundo que un hecho histórico biográfico.

El querer evaluar cualquier cosa singular según su finalidad presenta un problema conceptual muy arduo, ya que el espinosismo, al ser un mecanicismo radical 
fundamentado en un racionalismo absoluto ${ }^{12}$, intenta excluir el concepto de finalidad. Cuando hablamos entonces de la finalidad del Estado, es una manera retórica de hablar, ya que, al ser una cosa singular, el Estado no tiene finalidad puesto que el Apéndice de la primera parte de la Ética excluyó la finalidad de toda la naturaleza: "Mas para mostrar ahora que la naturaleza no tiene fin alguno prefijado, y que todas las causas finales son, sencillamente, ficciones humanas, no harán falta muchas palabras" (Spinoza 1987 I Ap., 112). Así, el Estado, como toda cosa singular, obedece a la única ley natural fundamental que es la ley del conatus. Por lo tanto, todo Estado tiene como tendencia el perseverar en su ser, y asimismo el durar, al hacer esfuerzo para mantener la relación cuantitativa entre sus partes, que lo determina como individuo. Se puede así restablecer el vínculo entre política y física, excluyendo la finalidad de la política y haciendo del conatus el único patrón con el cual comparar las diferentes cosas singulares. Toda la política está entonces regida por la nueva teoría de la esencia, obligándonos a regresar al nivel ontológico para pensar la política fundamental.

Una sociedad es también una cosa singular compuesta por una multiplicidad de individuos cuyas potencias se componen para crear un individuo de nivel superior. Por lo tanto, el proceso de formación de una sociedad no es diferente del proceso de formación de cualquier otra cosa singular, ya sea un cuerpo humano, una molécula, una galaxia o una familia, y no puede ser evaluado de manera distinta. Siempre se trata de un problema de composición de potencias que se pueden mantener juntas gracias a cierta relación determinada entre ellas. Para que la esencia de esta cosa singular que se llama "sociedad" pueda perseverar en su ser, debe mantener la relación cuantitativa entre sus partes, relación que la define como individuo compuesto. Así, lo que permite a una cosa singular permanecer en su ser, es cierta relación de paz entre sus partes. Ahora, dado que este fenómeno de paz interna entre las partes afecta al proceso de composición de toda cosa singular, la paz se debe entender de una manera muy amplia, como una adecuación pacífica que mantiene la unidad entre las partes que componen una cosa singular. El concepto de paz, de manera prioritaria, se debe entender como una paz interior ${ }^{13}$, es decir, como un estado en el cual ninguno de los componentes de la sociedad (o de cualquier cosa singular) entra en contradicción radical con los otros. El contrario de la paz entonces no es tanto la guerra entre cosas singulares que la sedición interna, entre los componentes que configuran todas las cosas singulares.

La paz es uno de los conceptos fundamentales del espinosismo, pero tal como Spinoza modificó la teoría de la esencia, el concepto de paz adquiere una definición muy particular en su obra. Podemos primero recordar que éste figura explícitamente

12 "Le rationalisme absolu, imposant la totale intelligibilité de Dieu, clef de la totale intelligibilité des choses, est donc pour le spinozosme le premier article de foi" (Gueroult 1968, 12).

13 El carácter interno de la paz se manifiesta en política en el hecho de que Spinoza teme mucho más la sedición interna que la violencia externa: "Es cierto, por lo demás, que la sociedad siempre corre más peligro por los ciudadanos que por los enemigos, [...]" (Spinoza 1986a VI 6, 157). 
en el subtítulo del Tratado Teológico-Político ${ }^{14}$. En este subtítulo, el concepto de República está en singular. Spinoza habla de la paz de la República $<$ Republicae pace $>$, manifestando que la paz de la cual está tratando es mucho más la paz interior a la sociedad que la paz externa entre varias repúblicas. Asimismo, la paz se puede asemejar a una armonía interna. El concepto de paz aparece también a lo largo del Tratado Político. Lo encontramos en el capítulo 5: "La paz, en efecto, no es la privación de la guerra, sino una virtud que brota de la fortaleza del alma, [...]" (Spinoza 1986a $\mathrm{V} 4,150)$. Existe así una concepción de la paz como adecuación entre las partes que permite a toda cosa singular perseverar en su ser. Tal como lo nota Charles Ramond (Ramond 2005), la paz, entonces, tiene varios nombres. Que la llamemos pacto en política, composición en física, equilibrio en lo afectivo, no-contradicción en lógica o alianza en lo religioso, ninguna cosa singular puede permanecer en la existencia y perseverar en su ser sin presentar cierta paz entre sus diferentes elementos, por lo que simétricamente la existencia o la perseverancia en su ser de cualquier cosa singular manifiesta a posteriori la presencia de cierta paz en ella y de no-contradicción, es decir, de cierta racionalidad.

Entendemos entonces en qué medida la duración puede ser el patrón que nos permita evaluar los diferentes regímenes políticos, ya que es en realidad el único patrón que nos permite evaluar cualquier cosa singular. Dado que las cosas singulares no presentan finalidades, lo único que podemos evaluar es lo que manifiestan al existir, es decir, la racionalidad que se evidencia en su misma duración, puesto que, para durar, las partes no pueden estar en contradicción las unas con las otras. Según esta lógica, un matrimonio que dura es mejor que un matrimonio que no dura, una vida que dura es mejor que una vida que no dura, un acuerdo entre Estados que dura es mejor que un acuerdo que no dura. No son mejores en nombre de valores trascendentes ni de finalidades, sino que son mejores en este sentido que su misma duración manifiesta su no-contradicción y su racionalidad. Una amistad que dura manifiesta, por su misma duración, que realiza en cierta medida y hasta cierto nivel los intereses de los dos amigos. Igualmente, en ciencia, una hipótesis que dura manifiesta su superioridad frente a una hipótesis que se puede refutar inmediatamente ${ }^{15}$.

La justificación de la duración como patrón de evaluación de los regímenes políticos es entonces la consecuencia lógica de la teoría de la esencia de Spinoza que hace de la duración la manifestación de la racionalidad y de la paz interna que evidencia toda cosa singular por su simple existencia. Dado que la sociedad es una cosa singular compuesta por partes, la perseverancia en su ser (o duración) manifiesta el hecho de que las partes se componen y que no están en contradicción radical entre ellas. Por lo tanto, la concepción espinozista de la política implica que el regulador social sea la

14 Su título completo es: Tractatus theologico-politicus, continens dissertaciones aliquot, quibus ostenditur libertatem philosophandi non tantum salva pietate et reipublicae pace posse concedi, sed eandem nisi cum pace reipublicae ipsaque pietate tolli non posse.

15 Es el modelo epistemológico que presenta el Tratado de la reforma del entendimiento, modelo según el cual una idea verdadera es una idea productiva. 
potencia, en este sentido de que, pasado cierto nivel de contradicción interna, las partes entrarán en sedición o se rebelarán contra la suprema potestad. De allí la evaluación en términos de duración, dado que hasta que las partes (o en este caso los actores sociales de cualquier nivel o índole) se compongan, manifiestan el valor de la entidad compuesta en este sentido que realiza el interés y la utilidad de cada una de éstas. Según la lógica espinozista, la duración de una sociedad manifiesta mínimamente la aceptación de ésta por los grupos y los individuos que la componen.

\section{Conclusión: Duración, democracia y política del deseo}

El hecho de evaluar la política según las leyes comunes de la física y de la perseverancia de la sociedad en su ser parece inaceptable a muchos, ya que construye un vínculo moralmente injustificable entre el ser y el deber-ser. No faltarán los contemporáneos que querrán oponer a Spinoza el hecho de que las tiranías duran, por lo que la duración no parece decirnos nada de lo bueno o de lo malo de los regímenes políticos. Políticamente y ontológicamente, el espinosismo sería simplemente un elogio de la fuerza más brutal. Sin embargo, estos argumentos son más débiles que lo que parecen. Primero porque la evaluación cualitativa presenta dificultades insuperables. Nadie es capaz de determinar por qué razón se debería utilizar cierto valor y no otro para evaluar los regímenes políticos, ya que cada ciudadano puede esperar algo diferente de la política. Menos aún podrán convencer a sus opositores de manera pacífica para que adopten sus valores. Segundo, la paz que garantiza la duración no se debe confundir con la simple ausencia de guerra. Una sociedad que mantiene sus partes juntas por el simple temor no goza de paz $^{16}$, solo contiene momentáneamente la violencia, en el doble sentido del verbo contener ("llevar en sí” y "hacer obstáculo a”). Los regímenes basados exclusivamente en el terror siempre terminan generando potencias que les son superiores al interior o al exterior. Cuando el Antiguo Régimen francés llegó a tales niveles de contradicción interna que muchos ciudadanos no veían mínimamente sus intereses básicos realizados por este, se posibilitó la Revolución francesa. El tercer Reich que tenía que durar mil años duró veinte. Para quienes tuvieron que padecer estos veinte años, fueron demasiados, pero estamos muy lejos de la duración de mil años que tenía prevista Hitler. Por su irracionalidad, el conatus del tercer Reich, en cuanto forma una cosa singular, encontró fuera de él potencias exteriores que se compusieron para destruirlo. No son valores que

16 "De una sociedad cuyos súbditos no empuñan las armas, porque son presa del terror, no cabe decir que goce de paz, sino más bien que no está en guerra. La paz, en efecto, no es la privación de guerra, sino una virtud que brota de la fortaleza del alma, ya que la obediencia (por el $\S 19$ del capítulo II) es la voluntad constante de ejecutar aquello que, por decreto general de la sociedad, es obligatorio hacer. Por lo demás, aquella sociedad cuya paz depende de la inercia de unos súbditos que se comportan como ganado, porque solo saben actuar como esclavos, merece más bien el nombre de soledad que sociedad" (Spinoza 1986a V 4, 150-151). 
derrotaron al tercer Reich, sino potencias que, aunque no compartían casi ningún valor, pudieron componerse para derrotarlo. Paradójicamente, a escala de la historia humana, los regímenes que no satisfacen un mínimo a sus ciudadanos no duran siglos y siempre encuentran potencias superiores tanto en su interior como al exterior.

Entendemos entonces que la teoría política de Spinoza, siendo una teoría de la potencia, le lleve paradójicamente a un elogio de la democracia, no en nombre de los valores democráticos, sino en nombre de la ausencia de valores democráticos. La democracia espinozista es superior a los otros regímenes políticos porque es la forma política que permite que la sociedad dure, porque exterioriza las ideas para objetivarlas. No podemos evaluar las ideas de los ciudadanos en términos de valores. Nadie puede demostrar que el voto proporcional es más o menos justo que el voto mayoritario, ya que deberíamos responder a la pregunta: ¿más justo según qué concepción de la justicia, y por qué haber escogido esta concepción y no otra? En cambio, al hacer votar a los ciudadanos, podemos muy fácilmente evaluar de manera objetiva lo que estos quieren ${ }^{17}$. La política del deseo en contra de la política de los valores presenta dos ventajas. Primero, dado que nada es legítimo (en este sentido que podría estar por encima de la legalidad), tampoco ninguna reivindicación es ilegítima. Dado que ningún valor a priori deslegitimiza las reivindicaciones de los grupos sociales, todos pueden presentar sus programas, sus preferencias y sus visiones del mundo. Mientras no sean mayoritarias, no pueden imponerlas (ni siquiera en nombre de sus valores), pero tienen el derecho de hacer lo que es legalmente posible para que sean votadas. Segundo, como la mayoría no dicta valores a la sociedad sino únicamente los deseos de los ciudadanos en un momento determinado de la historia, ninguna mayoría puede imaginar que su legitimidad proviene de la razón ni del bien, sino únicamente de la levedad de las matemáticas, por lo que su peso sobre las minorías será mínimo. En la democracia espinozista, nadie puede afirmar que legalizar el matrimonio homosexual, legalizar la prostitución, aumentar los impuestos directos en vez de los indirectos, está mal, pero tampoco que está bien, sino que el voto mayoritario manifiesta la manera según la cual una sociedad desea vivir en un momento dado de su historia. Así, las democracias duran porque al objetivar las contradicciones pueden resolverlas de manera pacífica. En caso de conflicto, no se evalúan axiológicamente las ideas de las dos posiciones, sino que se cuentan los deseos expresados en los votos. La solución pacífica es el externalizar las ideas para contarlas. Al hacer esto, se rompe la frontera

17 Incluso en su descripción de la monarquía ideal, Spinoza aconseja al rey aplicar las ideas mayoritarias en el Consejo para evitar sediciones sociales, tal como si hasta la monarquía debería funcionar según la ley mayoritaria y por lo tanto por la ley de los números y de la matemática. Tal como si la monarquía ideal debería ser, en su estructura intima, una de las modalidades posibles de la democracia: "Así pues, el rey, bien porque le guía el miedo a la multitud o porque quiere ganarse a la mayor parte de la multitud armada, bien porque su generosidad le lleve a velar por el bienestar público, siempre ratificará aquella opinión que haya obtenido mayor número de votos, es decir, la que es más útil para la mayor parte del Estado" (Spinoza 1986a VII 11, 185). 
entre consentimiento y obediencia. Efectivamente, toda obediencia es un tipo de consentimiento, ya que obedecer es decidir obedecer, o consentir obedecer, porque, como lo muestran los ejemplos heroicos de algunos resistentes en diferentes países, siempre uno puede resistirse hasta la muerte: "Cualquiera que sea, en efecto, el motivo por el que un hombre se decide a cumplir las órdenes de la suprema potestad, ya sea porque teme la pena, porque espera conseguir algo, o porque ama a la patria, o porque le impulsa cualquier otro sentimiento, decide según su propio juicio $\mathrm{y}$, sin embrago, obra por mandato de la suprema potestad" (Spinoza 1986b XVII 2, 351). Pero, sobre todo, si la democracia espinozista es el régimen que más dura, borrando la diferencia entre obedecer y consentir, es porque al excluir cualquier tipo de valor absoluto previo al voto, es la que mejor encarna la rueda de la democracia. Tal como lo nota Derrida, la democracia es el sistema en el cual el ciudadano es a la vez la voz y el oído de la ley, porque emane de él y se impone a él. Por esta figura circular ${ }^{18}$, en democracia, uno obedece a sí mismo por lo que evita las contradicciones sediciosas, dado que el ciudadano debería estar en contradicción con sí mismo.

La justificación de la duración como criterio de evaluación política en Spinoza se fundamenta entonces tanto desde el punto de vista epistemológico (es más eficiente que las evaluaciones según los valores), como ontológico (al ser una cosa singular, un régimen está sometido a la estructura de la paz interna y de la utilidad generalizada de los componentes de toda cosa singular). Pero además se justifica desde el punto de vista de lo deseable (ya que paradójicamente conlleva a una concepción democrática y leve de la política). Este criterio de la duración no significa que la política espinozista no disponga de reguladores sociales que permitan cambios y eventualmente revoluciones (Vinolo 2016b). Pero el proceso regulador es inmanente. La duración es el único regulador social, ya que, como toda cosa singular, mientras un régimen dure, manifiesta su racionalidad en este sentido que no hay existencia sin un mínimo de paz entre los componentes de cierta totalidad. En una filosofía plenamente inmanente, solo la ontología puede alumbrar la política y exportar en ésta su criterio fundamental de la duración o de la permanencia de cada cosa singular en su ser, para llegar a evaluaciones comunes y consensos.

"Mais je n'imagine pas qu' on ait pu jamais penser et dire, ne serait-ce qu'en grec, 'démocratie', avant le roulement de quelque roue. Quand je prononce 'roue', je ne me réfère pas encore et pas nécessairement à la possibilité technique de la roue. Mais plutôt, plus tôt, à la rotondité d'un mouvement diratoire, à la rondeur d'un retour à soi d'avant toute distinction entre physis et tekhnè, physis et nomos, physis et thesis, etc" (Derrida 2003, 29). [Derrida subraya]. 


\section{Referencias bibliográficas}

Aron, R. (2013), Liberté et égalité, Cours au Collège de France. Paris: EHESS.

Bergson, H. (1999), Ensayo sobre los datos inmediatos de la consciencia. Salamanca: Sígueme.

Camus, R. (2011), Décivilisation. Paris: Fayard.

Deleuze, G. (1972), L’Anti-CEdipe, Capitalisme et schizophrénie. Paris: Éditions de Minuit. Editores.

(1996), Spinoza y el problema de la expresión. Barcelona: Muchnik

Derrida, J. (2003), Voyous. Paris: Galilée.

Descartes, R. (1984, 1996), Reglas para la dirección del espíritu, Regla IV. Madrid: Alianza Editorial.

Gueroult, M. (1968, 1997), Spinoza, I, Dieu. Paris: Aubier Montaigne.

Lordon, F. (2013), La société des affects, Pour un structuralisme des passions. Paris : Seuil.

Marion, J-L. (2013), Sur la pensée passive de Descartes. Paris: PUF. (2008), Sobre la ontologia gris de Descartes, Ciencia cartesiana y saber aristotélico en las Regulae. Madrid: Escolar y mayor.

(1986), Sur le prime métaphysique de Descartes, Constitution et limites de l'onto-théo-logie dans la pensée cartésienne. Paris: PUF.

Matheron, A. (2011), "L'indignation et le conatus de 1'État spinoziste”, Études sur Spinoza et les philosophies de l'âge classique. Lyon: ENS éditions, 219-229.

Pedretti. M. (2001), La figure du désobéissant en politique. Paris: L’Harmattan.

Platón. (1986, 1988), "Fedro". Diálogos, III, 309-413. Madrid: Gredos.

Ramond, C. (2016), Spinoza contemporain, Philosophie, Éthique, Politique. Paris : L'Harmattan.

(2005), "La loi du nombre (ou la démocratie comme 'régime absolu')". En Spinoza, Euvres complètes V, Traité Politique, 7-43. Paris: PUF.

(1995), Qualité et quantité dans la philosophie de Spinoza. Paris: PUF.

Spinoza (2007a), "Carta 50 a Jarig Jelles". Epistolario, 203-204. Buenos Aires: Colihue.

(2007b), “Carta 56 a Hugo Boxel”. Epistolario, 219-223. Buenos Aires: Colihue.

(1990), Tratado breve. Madrid: Alianza Editorial.

(1987, 2014), Ética. Madrid: Alianza Editorial.

(1986a, 2013), Tratado Político. Madrid: Alianza Editorial.

(1986b, 2012), Tratado Teológico-Político. Madrid: Alianza Editorial.

Vinolo, S. (2016a), "Spinoza et l'argent, La politique comme économie des passions". Revue Philosophique de Louvain 114(2): 221-244. 
(2016b), "Spinoza y la indignación: Una concepción evolucionista de la política". Revista de la Pontificia Universidad Católica del Ecuador 103: 461-485.

(2015), "La levedad democrática, Elogio de una política sin valores". Revista de la Pontificia Universidad Católica del Ecuador 101: 39-59. (2013), "La majorité contre la foule“. Cités 53: 87-106. 